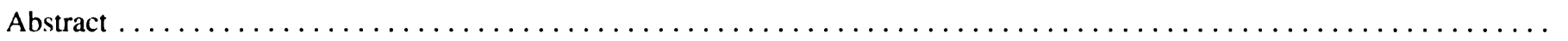

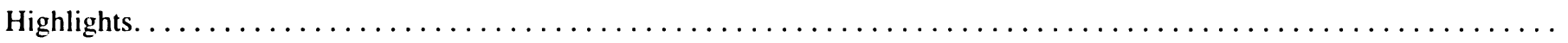

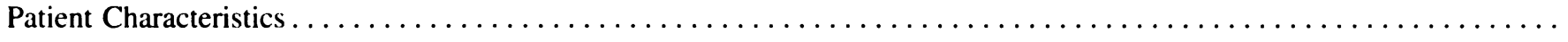

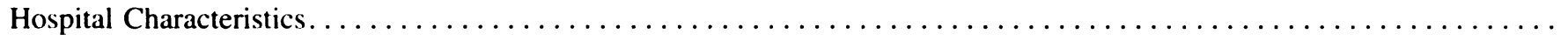

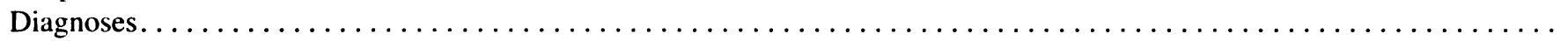

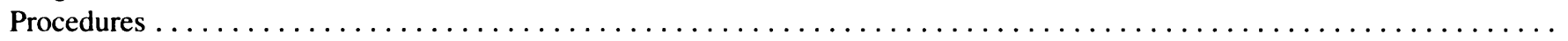

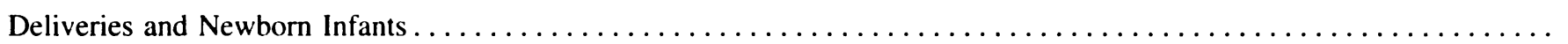

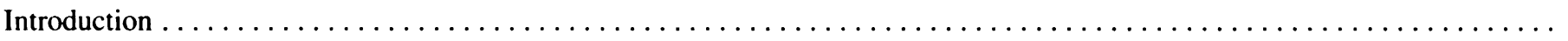

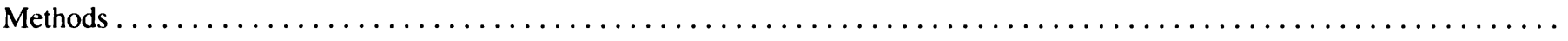

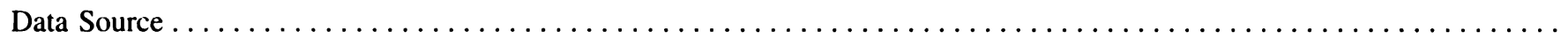

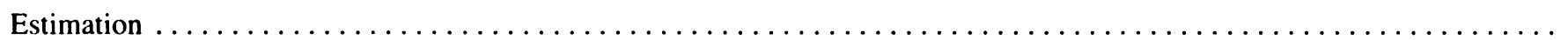

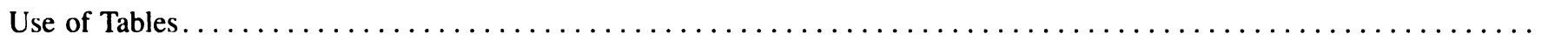

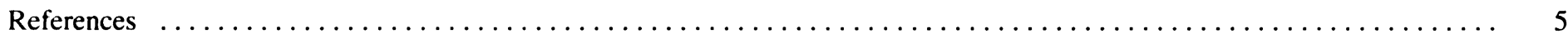

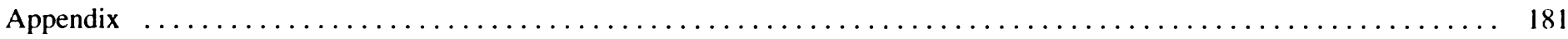

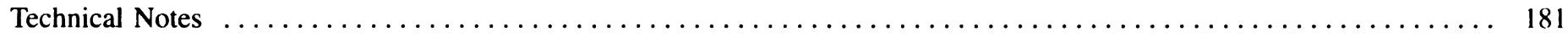

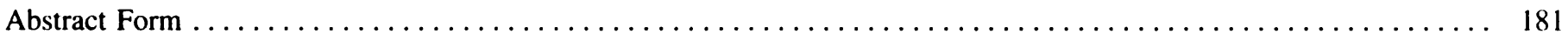

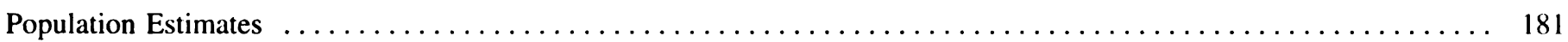

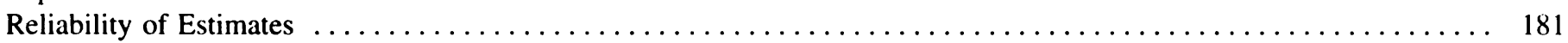

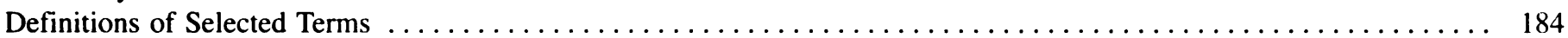

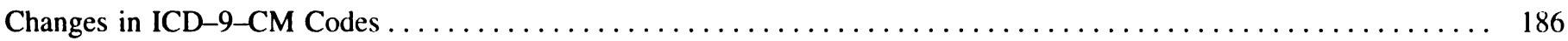

\title{
Text Figures
}

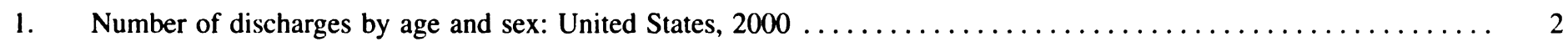

2. Average length of stay in days by region: United States, selected years $1970-2000 \ldots \ldots \ldots \ldots$

3. Number of discharges for selected diagnoses by age: United States, $2000 \ldots \ldots \ldots$

4. Rate of discharges with a diagnosis of human immunodeficiency virus by region: United States, 2000 . . . . . . 3

5. Rate of discharges with coronary artery procedures by sex: United States, $2000 \ldots \ldots \ldots$

6. Percent distribution of discharges with deliveries by length of stay: United States, selected years 1980-2000...... 4

\section{Detailed Tables}

\section{Tables on Patient and Hospital Characteristics}

1. Number and rate of discharges from short-stay hospitals and of days of care, with average length of stay, by age:

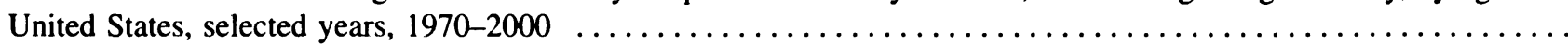

2. Number, percent distribution, and rate of discharges from short-stay hospitals and of days of care, with average length of stay, by sex and age: United States, 2000 (1)

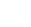
3 (1)

3. Number and rate of discharges from short-stay hospitals and of days of care, with average length of stay, by sex, age, and geographic region: United States, 2000

4. Number of discharges from short-stay hospitals and of days of care, with average length of stay, by principal expected source of payment, sex, age, and geographic region: United States, 2000 .

5. Number and percent distribution of discharges from short-stay hospitals and of days of care, with average length of stay, by bed size of hospital, sex, age, and geographic region: United States, 2000 